\title{
MAGNETIC AND DIELECTRIC PROPERTIES OF POLYMER-CERAMIC COMPOSITES SYNTHESIZED USING A MELT COMPOUND TECHNIQUE
}

\author{
RAJSHREE JOTANIA ${ }^{1}$ \\ Department of Physics, University School of Sciences, Gujarat University, \\ Ahmedabad-380 009, Gujarat, India \\ ${ }^{1}$ rbjotania@gmail.com \\ CHETAN CHANMAL \\ Polymer Science \& Engineering Division National Chemical Laboratory, Address \\ Pune-411 008, Maharashtra, India \\ cvchanmal@yahoo.com \\ JYOTI JOG \\ Polymer Science \& Engineering Division National Chemical Laboratory, Address \\ Pune-411 008, Maharashtra, India \\ jp.jog@ncl.res.in
}

\begin{abstract}
Polymer composites have emerged as a new class of materials, which have attracted technologist as they display novel properties compared to traditional materials and dramatically improves the performance properties of polymer system. We have synthesized hexaferrite-polymer composites of Polyvinylidene Fluride (PVDF) with $\mathrm{BaCa}_{2} \mathrm{Fe}_{16} \mathrm{O}_{27}(2.0,5.0 \%$ wt/vol.) using a melt compounding technique. $\mathrm{BaCa}_{2} \mathrm{Fe}_{16} \mathrm{O}_{27}$ hexaferrite powder was prepared using a microemulsion technique and directly mixed in melted PVDF, following by a low temperature hot pressing. The composites of PVDF with various weight percent of $\mathrm{BaCa}_{2} \mathrm{Fe}_{16} \mathrm{O}_{27}(2.0 \& 5.0 \%$ wt/vol.) were processed via melt mixing at $200^{\circ} \mathrm{C}$, with $60 \mathrm{rpm}$ for 5 minutes. The films of uniform thickness are about $0.5 \mathrm{~mm}$ is obtained by a compression molded instrument at $200^{\circ} \mathrm{C}$ under 5 -ton pressure. The influence of $\mathrm{BaCa}_{2} \mathrm{Fe}_{16} \mathrm{O}_{27}$ hexaferrite contents on magnetic and dielectric properties of composite was investigated. The prepared PVDF- $\mathrm{BaCa}_{2} \mathrm{Fe}_{16} \mathrm{O}_{27}$ composite thick films were characterized for their magnetic; dielectric and thermal behavior employing magnetic, dielectric and thermal analysis (TGA/DTA). Maximum saturation magnetization was obtained for $5 \%$ $\mathrm{wt} / \mathrm{vol}$. of barium calcium hexaferrite composite.
\end{abstract}

Keywords: polymer-cceramic composite; melt compound technique; dielectric and magnetic properties.

\section{Introduction}

Polymer composites consisting of ferrite particles embedded in a non-magnetic polymer matrix is a relatively new area in material science and engineering. Polymer based composites have attracted much attention because of their flexibility, tunable properties and easy processibility. These materials offer low cost and rapid fabrication, and they 
combine the advantageous properties of magnets and plastics [1, 2]. Ferrite -polymer composites are unique materials because of their large potential applications in electromagnetic wave shielding, microwave devices, information storage media and processing information. The combination of the magnetic particles with polymer matrix leads to formation of ferromagnetic polymer composite possessing combined electrical and magnetic properties. This property of the composite can be used an electromagnetic shielding material.

Several methods have been proposed to prepare polymer composites, such as sol-gel reaction [3], intercalative polymerization [4], and polymerization via melt processing [5], depending upon the nature of the nano-particles and types of polymeric matrix. The final properties of these composites depend upon various parameters like size of particles, method of preparation of composite and dispersion of particles into the polymer matrix [6-8]. We have selected Polyvinylidene Fluoride (PVDF) polymer as it is a highly nonreactive, semi-crystalline and pure thermoplastic fluoro-polymer with pyro and piezoelectric properties.

In present work, the polymer PVDF based composites consisting of $\mathrm{BaCa}_{2} \mathrm{Fe}_{16} \mathrm{O}_{27}$ ferrite filler with varying weight percentage has been reported, The aim of present study is to investigate how wt $\%$ of fillers affects the thermal, dielectric and magnetic properties of such composites.

\section{Experimental}

\subsection{Sample preparation}

PVDF grade, Solef 1008 (with weight-average molecular weight of $100 \times 10^{3} \mathrm{~g} / \mathrm{mol}$ ) procured by Solvay Belgium is used as raw material. $\mathrm{BaCa}_{2} \mathrm{Fe}_{16} \mathrm{O}_{27}$ hexaferrite nanoparticles were prepared using a microemulsion technique [9]. Polymer based composites were prepared using a melt mixing technique. $\mathrm{BaCa}_{2} \mathrm{Fe}_{16} \mathrm{O}_{27}$ hexaferrite powder was directly mixed in melted PVDF, following by a low temperature hot pressing. The composites of PVDF with various weight percent of $\mathrm{BaCa}_{2} \mathrm{Fe}_{16} \mathrm{O}_{27}(2.0 \&$ $5.0 \% \mathrm{wt} / \mathrm{vol}$. , codes FC1, FC2 respectively) were prepared via a melt mixing in Thermo Haake Polylab batch mixer at $200^{\circ} \mathrm{C}$, with $60 \mathrm{rpm}$ for 5 minutes. The films of uniform

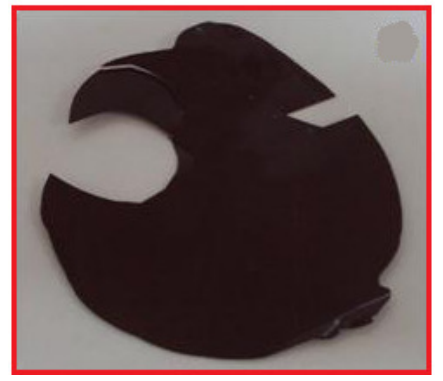

Fig. 1. Thick film of PVDF/ $\mathrm{BaCa}_{2} \mathrm{Fe}_{16} \mathrm{O}_{27}$ composite 
thickness are compression molded at $200^{\circ} \mathrm{C}$ under 5-ton pressure using Carver Press (Germany). The thickness of the films is about 0.4 to $0.5 \mathrm{~mm}$. Prepared thick film is shown in figure 1.

\subsection{Sample characterization}

The TGA and DTA curves of PVDF/ $\mathrm{BaCa}_{2} \mathrm{Fe}_{16} \mathrm{O}_{27}$ composite samples were recorded using a thermo gravimetric analyzer model no. TGA-50 and Differential Thermal Analyzer DTA-50 (Shimadzu) between temperature range from 40 to $800^{\circ} \mathrm{C}$. The magnetic properties were investigated using VSM on an EG\&G Princeton Applied Research instrument (Model 4500). Complex dielectric permittivity measurement of PVDF and PVDF/ $\mathrm{BaCa}_{2} \mathrm{Fe}_{16} \mathrm{O}_{27}$ composites was carried out using Novo-control broadband dielectric spectrometer with the ZGS active sample cell equipped with temperature controller and Win-Fit software for data analysis. The dielectric response of material in the frequency ranging from $10 \mathrm{MHz}$ to $100 \mathrm{~Hz}$ at room temperature is measured by placing sample between two $20 \mathrm{~mm}$ gold plated electrodes. Quick drying silver paste is used to ensure good electrical contact. The real and complex permittivity were measured by using a LCR bridge (Agilent Model No. E4980A).

\section{Results and discussion}

\subsection{Thermal analysis}

TG and DTA curves are shown in figure 2. TG curves show three distinct steps of weight loss in both composite samples. The first step weight loss between $350^{\circ} \mathrm{C}$ to $400^{\circ} \mathrm{C}$ $(\sim 50 \%)$. This weight loss may be due to combustion of organic substances [10,11]. In the second step, a sharp weight loss between $400^{\circ} \mathrm{C}$ to $580^{\circ} \mathrm{C}(\sim 20$ wt. $\%$ in both cases) occurs. In the second step, the weight in both sample and is about 22 wt. \% in FC2

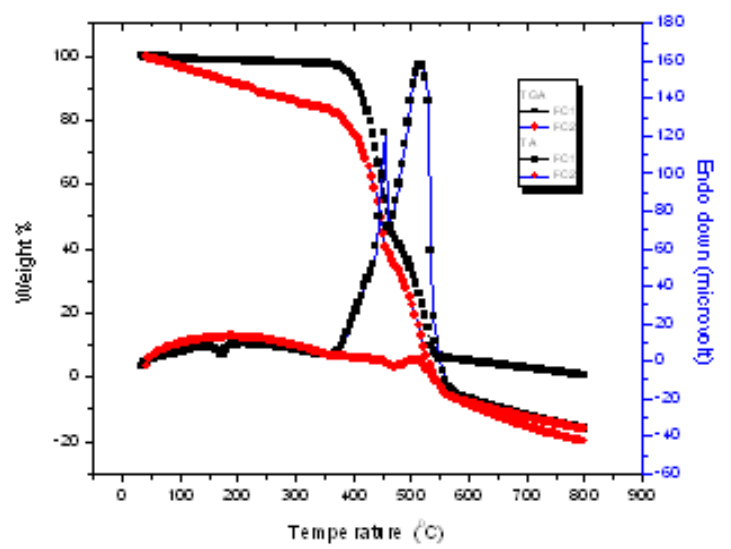

Fig. 2.TGA thermo gram and DTA curves of the composites with different filler contents 
sample. It can be seen from figure that there is no weight loss after $550^{\circ} \mathrm{C}$ indicate that organic material in samples was already completely eliminated $[12,13]$.

\subsection{Dielectric permittivity}

Figure 3 show the variation of the real part $\left(\varepsilon^{\prime}\right)$ of dielectric permittivity and imaginary part $(\varepsilon ")$ of dielectric permittivity of polymer-ferrite $(2 \%, 5 \%$ wt./v) composite respectively. The dielectric properties of polycrystalline ferrite composites arise mainly from the interfacial polarization and the intrinsic electric dipole polarization. The large values of $\left(\varepsilon^{\prime}\right)$ at lower frequencies are due to the predominance of $\mathrm{Fe}^{2+}$ ions, interfacial dislocation pile ups, oxygen vacancies, grain boundary defects, etc. The decrease in $(\varepsilon)$ with frequency is natural because of the fact that any species contributing to polarizability is bound to show lagging behind the applied field at higher frequencies.

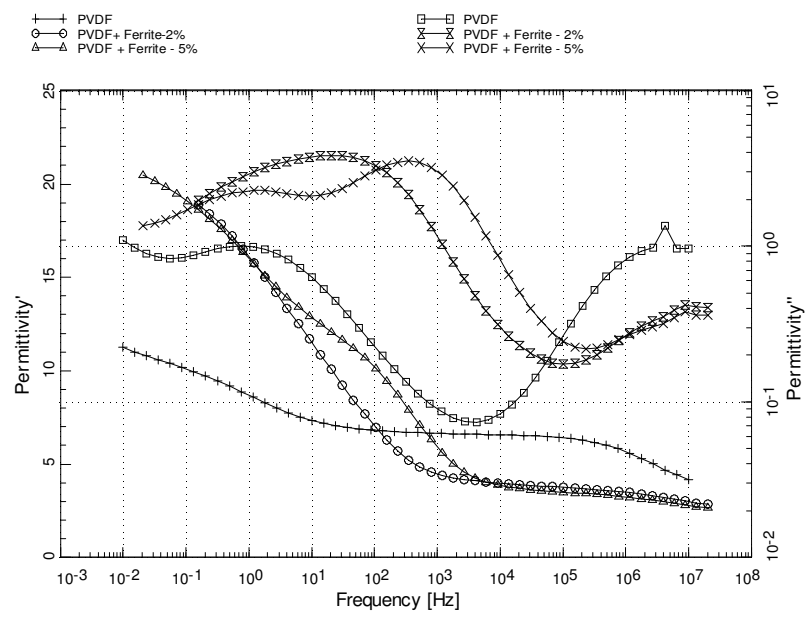

Fig.3 Dielectric permittivity (real, imaginary) as a function of frequency

\subsection{Magnetic property}

The field dependent magnetization of ferrite-polymer composites samples were measured at room temperature on a vibrating sample magnetometer with a maximum applied field of $15 \mathrm{kOe}$. The initial magnetization curves and M-H loops results are shown in fig 4(a) and 4 (b) respectively. It is clear from Fig 4 (a) that the saturation magnetization of FC2 sample is higher $(1.3 \mathrm{emu} / \mathrm{g})$ than $\mathrm{FC} 1$ sample $(0.2 \mathrm{emu} / \mathrm{g}$. $)$ this may be due to higher concentration (5\% wt./vol.) of Barium calcium hexaferrite powder in FC2 sample. 


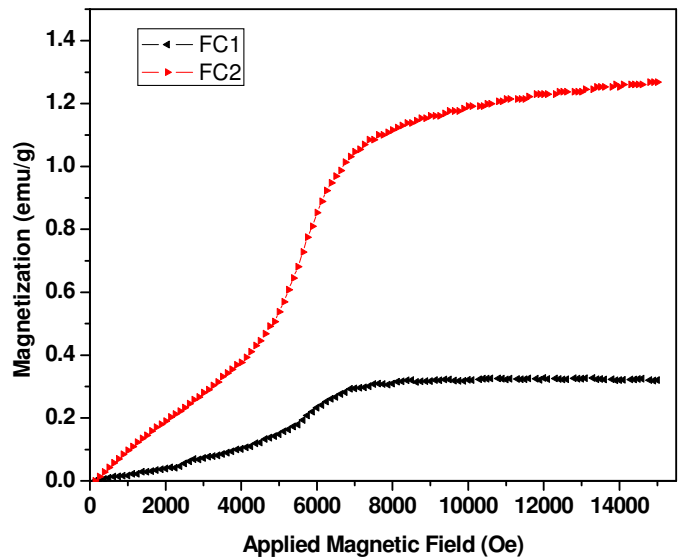

Fig. 4 (a). Initial magnetization curves for the composites with different filler contents.

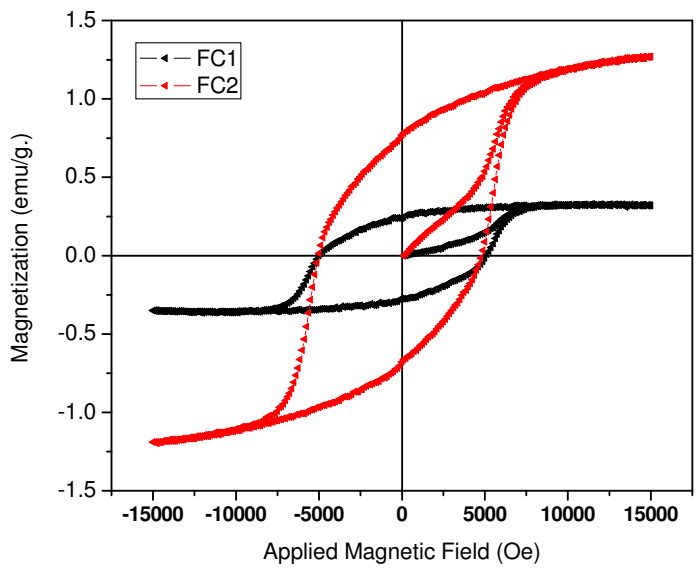

Fig. 4 (b). Hysteresis loops for the composites with different filler contents

\section{Conclusion}

This study was carried out in order to investigate study is to investigate the effect of magnetic fillers in polymer matrix on thermal, dielectric and magnetic properties of such composites. Basing on the obtained results the following conclusions were drawn:

1. It is possible to produce polymer composites that exhibit significant magnetic properties.

2. Maximum saturation magnetization was obtained for $5 \% \mathrm{wt} / \mathrm{vol}$. of barium calcium hexaferrite ferrite composite.

3. Comparison between two types of ferrite-polymer composites showed that the results for both had been comparable.

4. In future research authors want to increase content of magnetic filler 


\section{Acknowledgment}

The experimental investigations reported in this review paper have been carried out under INSA visiting scientist fellowship-2011.

\section{References}

1. Z. Zhang, L. Zhang, S. Wang, W. Chen, and Y. Lei, Polymer, 42, 8315 (2001).

2. Y. Gotoh, R. Igarashi, Y. Ohkoshi, M. Nagura, K. Akamatsu, and S. Deki, J. Mater. Chem., 10, 2548 (2000).

3. J. L. W. Noell, G.L. Wilkes, D.K. Mohanty, and J.E. McGrath,J. Appl. Polym. Sci., 40, 1177 (1990).

4. P. C. Le-Baron, Z. Wang, and T. J. Pinnavaia, Appl. Clay Sci.,15, 11 (1999).

5. R. A. Vaia, K. D. Jandt, E. J. Kramer, and E. P. Giannelis, Macromolecules, 28, 8080 (1995).

6. C. K. Chiang, R. Popielarz Ferroelectrics, 275, 1 (2002).

7. G. A. Kontos, A. L. Soulintzis, P. K. Karahaliou, G.C Psarras, S. N. Georga, C. A. Krontiras, M. N. Pisanias Polymer Letters, 1, 781 (2007).

8. G. C.Psarras, K.G.Gatos, P.K. Karahaliou, S.N. Georga, C.A. Krontiras, J. Karger- Kocsis Express Polymer Letters, 1, 837 (2007).

9. R. B. Jotania, R. B. Khomane, C. C. Chauhan, S. K. Menon and B. D. Kulkarni, J. Magn. Magn. Mater. 320, 1095 (2008).

10. J. Temuujin, M. Aoyama, M. Senna, T.vMasuko, C. Ando, H. Kishi, , J. Solid State Chem. 1773903 (2004).

11. X. He, Q. Zhang, Z. Ling, Materials Letters, 57 (20) 3031 (2003).

12. V.R. Caffarena, T. Ogasawara, J.L. Capitaneo, M.S. Pinho, Latin Am. Appl. Res. 36, 137 (2006).

13. D. Austissier, A. Podembski, D.C. Jacquiod J.Phys. IV France. 7(C1) 409 (1997). 